ISSN 0103-5150

Fisioter. Mov., Curitiba, v. 25, n. 1, p. 21-29, jan./mar. 2012 Licenciado sob uma Licença Creative Commons

\title{
Análise comparativa dos efeitos do ultrassom terapêutico e laser de baixa potência sobre a proliferação de células musculares durante a diferenciação celular
}

\author{
Comparative analysis between the effects of therapeutic ultrasound \\ and low power laser on the proliferation of $\mathrm{C} 2 \mathrm{C} 12$ myogenic \\ precursor cells during cell differentiation
}

\author{
Paola Pelegrineli Artilheiro ${ }^{[a]}$, Jean Lucas Parpinelli Barbosa ${ }^{[b]}$, Kristianne Porta Santos Fernandes ${ }^{[c]}$, \\ Tábata Santos de Oliveira ${ }^{[a]}$, Sandra Kalil Bussadori ${ }^{[c]}$, Raquel Agnelli Mesquita-Ferrari ${ }^{[c]}$ \\ [a] Mestranda em Ciências da Reabilitação, Universidade Nove de Julho (UNINOVE), São Paulo, SP - Brasil. \\ [b] Aluno do curso de biomedicina da Universidade Nove de Julho (UNINOVE), bolsista CNPq/PIBIC, São Paulo, SP - Brasil. \\ [c] Docente do Mestrado em Ciências da Reabilitação, Universidade Nove de Julho (UNINOVE), São Paulo, SP - Brasil, e-mail: \\ raquel.mesquita@gmail.com
}

\section{Resumo}

Introdução: Existe um grande interesse no estabelecimento de recursos e terapias a serem utilizados na tentativa de proporcionar um processo de reparo muscular de melhor qualidade e menor duração. 0 ultrassom terapêutico (US) e o laser de baixa potência (LBP) são recursos muito usados na prática clínica, porém são escassas, e por vezes contraditórias, as evidências científicas que determinam com segurança os parâmetros dosimétricos e metodológicos adequados. Objetivos: 0 objetivo do estudo foi analisar o efeito do US e do LBP sobre a proliferação celular durante a diferenciação de mioblastos C2C12. Materiais e métodos: Os mioblastos foram cultivados em meio de cultura de Eagle modificado por Dulbecco, contendo $10 \%$ de soro fetal bovino (SFB), sendo induzida a diferenciação pela adição de $2 \%$ de soro de cavalo durante 96 horas. Posteriormente, as células foram irradiadas com US pulsado a 20\%, $3 \mathrm{MHz}$ de frequência (intensidades de 0,2 e $0,5 \mathrm{~W} / \mathrm{cm}^{2}$, durante cinco minutos) ou submetidas ao tratamento com LBP (potência de saída de $10 \mathrm{~mW}$, densidade de energia de 3 e $5 \mathrm{~J} / \mathrm{cm}^{2}$, por 20 segundos). A proliferação celular foi avaliada após $24 \mathrm{~h}$ e 72h utilizando o método de MTT. Foram realizados três experimentos independentes, em cada condição citada e células não irradiadas serviram como controle. Resultados: Os resultados obtidos foram submetidos à análise estatística utilizando a Análise de Variância (ANOVA), teste Dunnet, para verificar diferenças entre o grupo controle (não tratado) e os grupos tratados com US e LBP, adotando significância de p $<0,05$. 
Os resultados evidenciaram que não houve diferença significativa na proliferação celular entre as células musculares submetidas a tratamento com ambos os recursos terapêuticos e as células controle, nos períodos de $24 \mathrm{~h}$ e $72 \mathrm{~h}$ após tratamento. Além disso, foi possível verificar que não houve aumento significativo no número de células após o período de $72 \mathrm{~h}$ quando comparado a $24 \mathrm{~h}$, confirmando o processo de diferenciação celular, conforme esperado. Conclusões: Conclui-se que o US e o LBP, nos parâmetros avaliados, não alteraram a proliferação de mioblastos em processo de diferenciação.

Palavras-chave: Ultrassom terapêutico. Laser. Mioblastos. Diferenciação. Proliferação.

\section{Abstract}

Introduction: There is great interest in establishing resources and therapies to be used in an attempt to provide a process of muscle repair better and shorter. Two features commonly used to facilitate the healing process are the therapeutic ultrasound and laser power, however, are still scarce and sometimes contradictory scientific evidence to determine with certainty the parameters and methodology necessary to acquire these goals. Objectives: Thus, the objective of present study was to evaluate the effect of therapeutic ultrasound (US) and low level laser GaAlAs $660 \mathrm{~nm}$ on the proliferation of C2C12 myoblasts. Materials and methods: The myoblasts were cultivated in culture medium of Eagle modified by Dulbecco, containing 10\% fetal bovine serum (FBS) and induced to differentiate by addition of $2 \%$ horse serum for $96 \mathrm{~h}$. Subsequently, cells were irradiated with US (20\%, $3 \mathrm{MHz}$, and intensities of 0.2 and $0.5 \mathrm{~W} / \mathrm{cm}^{2}$ for five minutes) or with LLL (output power of $10 \mathrm{~mW}$, density of 3 and $5 \mathrm{~J} / \mathrm{cm}^{2}$ for 20 seconds). The non-irradiated cells serve as controls. Three independent experiments were performed for each condition cited. Cell proliferation was evaluated after $24 \mathrm{~h}$ and $72 \mathrm{~h}$ using the MTT method. Results: The results were statistically analyzed using analysis of variance (ANOVA/Dunnet) to verify differences between control cells (untreated) and US/LLL treated groups. The results showed no significant differences in viability and cell proliferation between LLL or US treated cells and control cells after $24 \mathrm{~h}$ and $72 \mathrm{~h}$. Furthermore, it was observed no increase in the number of cells within the evaluation period after treatment, confirming the process of cell differentiation, as expected. Results: In conclusion, US and the LLL, employed under the parameters described does not alter C2C12 proliferation.

Keywords: Ultrasound therapy. Laser. Myoblasts. Differentiation. Proliferatio.

\section{Introdução}

A miogênese, ou a formação do músculo esquelético, é um processo altamente complexo que envolve a expansão de células musculares mononucleadas progenitoras ao longo da via miogênica até se tornarem mioblastos que se fundem para formar miotubos e que, finalmente, desenvolvem-se para se tornar miofibrilas do músculo esquelético maduro $(1,2)$.

A fusão de mioblastos de mamíferos ocorre em duas fases (3). Inicialmente, mioblastos se fundem a outros para formar pequenos miotubos. Adicionalmente, outros mioblastos se fundem a esses miotubos para formar miotubos maiores e maduros $(4,5)$. Durante a miogênese, a fusão de mioblastos em miotubos multinucleados é o passo terminal de diferenciação. Após isso, divisões mitóticas dentro dos miotubos ou fibras musculares não ocorrem mais. Núcleos extras, requeridos para crescimento muscular, são garantidos pelas células satélites, que são células musculares quiescentes localizadas abaixo da membrana basal da fibra muscular. Essas células representam a maior parte do potencial regenerativo diante da lesão e adaptação muscular ao exercício (2).

Nos diferentes estágios da miogênese, as células expressam distintos fatores regulatórios miogênicos envolvidos nesse processo de diferenciação. Desmina, Myf5 e MyoD são expressos em estágios iniciais, enquanto miogenina, fator regulatório de miogenina (MRF4) e miosina são expressos nos estágios mais tardios. A expressão desses fatores também é regulada por moléculas de sinalização extracelular da MEC e, também, por outros fatores envolvidos no contato célula-célula (6-8). 
A miogenina tem papel importante durante a miogênese, pois sua expressão marca o início da diferenciação e, consequentemente, quando se expressa a miogenina, as fibras musculares desenvolvem-se a partir dos mioblastos previamente formados (9). Por outro lado, a miostatina inibe a proliferação e diferenciação celular e se expressa predominantemente no desenvolvimento muscular (10). Estudos prévios relataram uma influência negativa da miostatina sobre a proliferação celular. Parâmetros testados levaram à confirmação de que a expressão de miostatina está fortemente inibida na fase terminal da diferenciação (10-12).

Quando um músculo sofre uma lesão, este tem a habilidade de iniciar um processo de reparo altamente organizado, de forma a prevenir a perda de massa muscular sendo capaz de restaurar a citoarquitetura dentro de um período de aproximadamente duas semanas. Esse processo é semelhante à miogênese, porém as células que participam são as células satélites $(13,14)$. Uma vez ativadas as células satélites proliferam, sendo então denominadas mioblastos, e também expressam os fatores reguladores miogênicos que controlam a proliferação e a diferenciação celular. Essas células se fundem a fibras musculares já existentes ou fundem-se a células satélites vizinhas para gerar novas fibras musculares $(15,16)$.

Há evidências de que o reparo tecidual possa ser estimulado por recursos terapêuticos como o ultrassom e laser de baixa potência, sendo esses recursos amplamente utilizados na prática clínica, porém, muitos dos estudos são contraditórios no que diz respeito aos parâmetros dosimétricos adequados para promover a regeneração muscular de forma mais rápida e de melhor qualidade diante dos diferentes tipos de lesão $(17,18)$.

Uma das modalidades terapêuticas mais utilizadas no tratamento de lesões de tecidos moles é o ultrassom, com o objetivo de proporcionar um processo de reparo muscular de melhor qualidade e menor duração. As ondas ultrassônicas causam vibrações e colisões moleculares, aumentando a atividade molecular e, por consequência, o aumento da temperatura (19).

A energia do US que penetra no organismo pode afetar as células e tecidos por meio de mecanismos térmicos e não térmicos, e as estruturas aquecidas, preferencialmente, pelo US incluem músculos, tendões, cicatrizes e a maioria das raízes nervosas. Evidências mostram que mecanismos não térmicos estariam envolvidos na produção dos efeitos terapêuticos primários do US, isto é, a estimulação da regeneração tecidual por meio do aumento da permeabilidade e difusão em nível de membrana celular, influxo de cálcio intracelular e alterações na atividade elétrica do tecido nervoso $(20,21)$.

Estudos in vitro demonstraram que os efeitos do US parecem ser dependentes do tipo celular, sendo que promovem a síntese de DNA em osteoblastos humanos, fibroblastos de gengiva e pele, células de periósteo, mas não em condrócitos (22). Com relação ao efeito do US sobre a proliferação celular, foi verificado inicialmente por Jonhs et al. (20) que o US contínuo e pulsado em intensidades de 0,1 a $0,7 \mathrm{~W} /$ $\mathrm{cm}^{2}$ era capaz de diminuir a taxa de crescimento celular, porém, em estudos posteriores, foi evidenciado que o US utilizado nas frequências de 1 e $3 \mathrm{MHz}$ em intensidades variadas promovia aumento da proliferação de fibroblastos e osteoblastos (23-28).

Os estudos mais recentes que avaliaram o potencial terapêutico do US foram realizados em osteoblastos (29-31), condrócitos (32-34), fibroblastos (35), células epiteliais (36) e células endoteliais (37).

O enorme potencial terapêutico do US está longe de ser estabelecido em virtude de novas aplicações serem adicionadas regularmente ao seu repertório (38). Assim, o melhor entendimento sobre os efeitos do US sobre as células musculares poderá contribuir de forma positiva para o estabelecimento de protocolos adequados para a melhoria do processo de reparo muscular e da recuperação clínica dos pacientes.

Outro recurso muito utilizado na prática clínica após lesões musculares é o laser de baixa potência, ou seja, aquele que possui baixa energia e ausência de potencial fototérmico. Existem diversos tipos, sendo os mais usados os que se encontram na porção óptica do espectro vermelho e do infravermelho (400 a $780 \mathrm{~nm}$ e 780 a $1 \mathrm{~mm}$ ). Seus fótons de energia são inferiores a 2,0 elétron-volt $(\mathrm{eV})$, portanto, inferiores à energia da ligação das moléculas biológicas e do DNA, não podendo quebrar ligações químicas e não sendo capazes de induzir mutação e carcinogênese $(39,40)$.

Estudos têm mostrado que o laser é capaz de influenciar a proliferação de fibroblastos $(41,42)$, osteoblastos (43) e células epiteliais (44). Além disso, essa terapia também possui efeitos sobre o colágeno e a síntese de colágeno $(45,42)$. Mais recentemente, um estudo analisou os efeitos do laser 
de AsGaAL nos parâmetros de $830 \mathrm{~nm}\left(0,3 \mathrm{~J} / \mathrm{cm}^{2}\right)$, $685 \mathrm{~nm}\left(0,6 \mathrm{~J} / \mathrm{cm}^{2}\right)$ e $670 \mathrm{~nm}\left(1,2 \mathrm{~J} / \mathrm{cm}^{2}\right)$ sobre células precursoras miogênicas e concluiu que a taxa de proliferação celular induzida por essas irradiações foi de $84,3 \%, 70,6 \%$ e $56,8 \%$, respectivamente (46).

Os efeitos miogênicos da irradiação com laser de baixa potência nas células se baseiam na capacidade de modulação de diversos processos metabólicos, mediante a conversão da energia luminosa aportada pelo laser por meio de processos bioquímicos e fotofísicos, os quais transformam a luz laser em energia útil para as células $(39,40,42,43,46,47)$.

0 efeito de bioestimulação depende da combinação de parâmetros como comprimento de onda, potência, intensidade e também do tipo celular a ser avaliado (39, 40, 42, 43, 46, 47).

Dificuldades na medição de variáveis relacionadas à dor e reparação tecidual em modelos animais ou em ambientes clínicos enfatizam a necessidade de estudos in vitro relacionados ao uso do laser (48).

Nosso grupo de pesquisa iniciou em 2007 os primeiros estudos avaliando o efeito de ambas as modalidades terapêuticas descritas em células precursoras miogênicas da linhagem C2C12, porém, detectou-se que esses recursos, nos parâmetros utilizados, não foram capazes de alterar a proliferação de mioblastos. Desse modo, nossa proposta foi avaliar, de forma comparativa, os possíveis efeitos do laser e ultrassom terapêutico sobre a proliferação das células musculares após $96 \mathrm{~h}$ de diferenciação com soro de cavalo.

É importante ressaltar que os mioblastos $\mathrm{C} 2 \mathrm{C} 12$ derivam de músculoesquelético de camundongos, exibem a maioria das características dos mioblastos normais e diferenciam-se em cultura, propiciando um bom modelo para estudar a regeneração muscular. Além disso, o uso de linhagens celulares em modelos para análise de proliferação celular elimina a possibilidade da influência da irradiação laser sobre a produção de fatores de crescimento por células não miogênicas contidas em culturas primárias, como fibroblastos e macrófagos $(1,46,49)$.

\section{Materiais e métodos}

\section{Cultura celular}

A linhagem celular C2C12, utilizada no presente trabalho, é um subclone da linhagem celular de mio- blastos $\mathrm{C} 2$, células derivadas de células satélites de ratos adultos $(35,36)$. Essas células foram cultivadas no meio de cultura de Eagle modificado por Dulbecco (DMEM, Cultilab, Campinas, SP, Brasil) contendo $10 \%$ de soro fetal bovino (SFB) (Cultilab, Campinas, SP, Brasil) e 1\% de antibiótico solução antimicótica (CULTILAB) e mantidas em estufa $37^{\circ} \mathrm{C}$, numa atmosfera úmida contendo $5 \%$ de $\mathrm{CO}_{2}$. 0 monitoramento do crescimento celular foi feito a cada $24 \mathrm{~h}$ e, quando a monocamada celular se tornava subconfluente para a perpetuação da linhagem celular, foi realizado o subcultivo com lavagem tampão PBS1X ( $\mathrm{NaCl} 140 \mathrm{mM}$; $\mathrm{KCl} 2,5 \mathrm{mM} ; \mathrm{Na}_{2} \mathrm{HPO}_{4} 8 \mathrm{mM} ; \mathrm{KH}_{2} \mathrm{PO}$ 1,4 mM; pH 7,4) e solução de tripsina. As células foram centrifugadas a $1200 \mathrm{rpm}$ e posteriormente ressuspensas em $1 \mathrm{~mL}$ de meio DMEM. A viabilidade das células foi avaliada por contagem com corante vital azul de Trypan $(0,4 \%)$ e foram utilizadas nos experimentos as células com viabilidade maior que $95 \%$.

Para indução da diferenciação, as células foram mantidas em meio DMEM contendo $2 \%$ de soro de cavalo por um período de $96 \mathrm{~h}$.

\section{Ensaio de proliferação celular (MTT)}

A metodologia utilizada para avaliação da viabilidade e proliferação celular se baseia na habilidade da enzima mitocondrial desidrogenase, encontrada somente em células viáveis, em clivar os anéis de tetrazólio do MTT (3-[4,5-Dimethylthiazol-2yl]-2,5diphenyltetrazolium bromide; Thiazolyl blue), formando cristais azuis escuros de formazana, os quais são impermeáveis às membranas celulares, ficando então retidos no interior das células viáveis (50). A posterior lise celular faz com que esses sais de formazana sejam liberados. 0 número de células viáveis é diretamente proporcional ao nível de cristais de azul de formazana formados.

Após o período de $96 \mathrm{~h}$ em que ficaram na presença de meio de diferenciação (DMEM com 2\% de soro de cavalo) as células musculares foram irradiadas com US pulsado a $20 \%, 3 \mathrm{MHz}$ de frequência (intensidades de 0,2 e $0,5 \mathrm{~W} / \mathrm{cm}^{2}$, durante cinco minutos) ou submetidas ao tratamento com LBP (potência de saída de $10 \mathrm{~mW}$, densidade de energia de 3 e $5 \mathrm{~J} / \mathrm{cm}^{2}$, por 20 segundos). Foram adicionadas $1 \times 10^{3}$ células/poço a placas de cultura de fundo chato de 96 poços, estéreis (20) e incubadas a $37^{\circ} \mathrm{C}$ e $5 \% \mathrm{CO}_{2}$ por $24 \mathrm{~h}$ e $72 \mathrm{~h}$. 
Ao término do período de incubação, foi feita a lavagem dos poços com PBS1X ( $\mathrm{NaCl} 140 \mathrm{mM} ; \mathrm{KCl} 2,5$ $\left.\mathrm{mM} ; \mathrm{Na}_{2} \mathrm{HPO}_{4} 8 \mathrm{mM} ; \mathrm{KH}_{2} \mathrm{PO} 1,4 \mathrm{mM} ; \mathrm{pH} 7,4\right)$ para remoção das células mortas e adicionado o MTT (0,5 $\mathrm{\mu g} / \mathrm{ml}) \quad$ (3-(4,5-dimethylthiazol-2-yl)-2,5,-diphenyltetrazolium bromide) (Sigma-Aldrich, St. Louis, MO, USA), e realizada a incubação das células por quatro horas a $37^{\circ} \mathrm{C}$ e $5 \% \mathrm{CO}_{2}$. Em seguida, foi adicionado isopropanol para solubilizar os cristais formados. Por fim, foi realizada a leitura da absorbância a $620 \mathrm{~nm}$ com auxílio de um leitor de placas (Anthos 2020, Anthos Labtec Instruments, Wals, Áustria) (Mosmann, 1983, Woerdenbag, 1994). Todos os experimentos foram repetidos três vezes, de forma independente, e cada amostra foi analisada em quadruplicata.

Para avaliar a morfologia das células musculares diante do tratamento com o US e LBP foram feitos registros fotográficos com auxílio do microscópio invertido (Nikon) antes da realização da avaliação da proliferação pelo método de MTT, ou seja, também após $24 \mathrm{~h}$ e $72 \mathrm{~h}$.

\section{Análise estatística}

As comparações entre os grupos foram feitas utilizando análise de variância (ANOVA). 0 teste de Dunnett foi utilizado para determinar diferenças significativas entre os grupos experimentais e o grupo controle. Valores de $\mathrm{p} \leq 0,05$ foram considerados estatisticamente significativos. Os dados foram analisados por meio do programa GraphPad Prism 4.0 (GraphPad Software, San Diego, CA, EUA).

\section{Resultados}

\section{Efeitos do US e LBP sobre a proliferação celular}

Os resultados permitiram verificar que não houve diferença significativa na proliferação celular, avaliada pelo método MTT, entre as células musculares submetidas a tratamento com ambos os recursos terapêuticos e as células controle, tanto no período de 24h (Gráfico 1) quanto no período de 72h (Gráfico 1 ).

Além disso, foi possível verificar que não houve modificação significativa no número de células quando comparados os períodos de $24 \mathrm{~h}$ e $72 \mathrm{~h}$ de

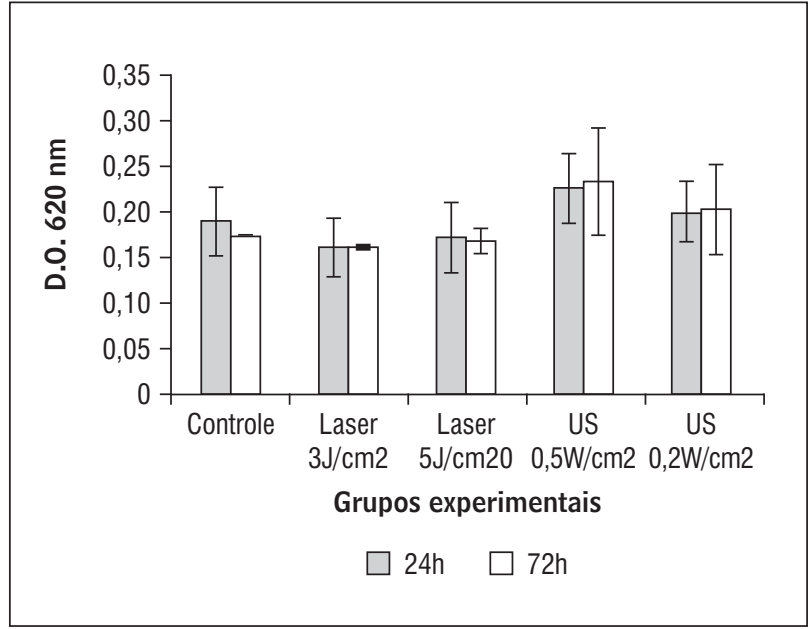

Gráfico 1 - Avaliação da proliferação e viabilidade de células musculares cultivadas em meio regular ( $10 \%$ de SFB) por 24h e 72h, na ausência (controle) e presença de tratamento com US e LBP, não apresentando aumento significativo no número de células dentro dos períodos de $24 \mathrm{~h}$ e $72 \mathrm{~h}$ após o tratamento, confirmando o processo de diferenciação celular

Fonte: Dados da pesquisa.

incubação após o tratamento com os recursos, confirmando o processo de diferenciação celular, conforme esperado (Gráfico 1).

Com relação à morfologia das células musculares também foi possível observar que os recursos terapêuticos utilizados não provocaram alterações evidentes, quando avaliados de maneira qualitativa por dois examinadores experientes de forma independente e cega. Como não existiram diferenças, apenas uma figura representativa de cada grupo experimental foi adicionada (Figura 1).

\section{Discussão}

Segundo Johns (20), a cultura celular é, por definição, um artefato; no entanto, permite que o investigador tenha um controle rigoroso sobre diversas variáveis do processo e possa fazer questionamentos de maneira mais sistemática. Portanto, estudos in vitro avaliando o potencial do US e laser de baixa potência são importantes complementos dos estudos in vivo, e podem trazer maiores conhecimentos de forma a permitir a utilização desse recurso de forma mais eficaz e segura. 


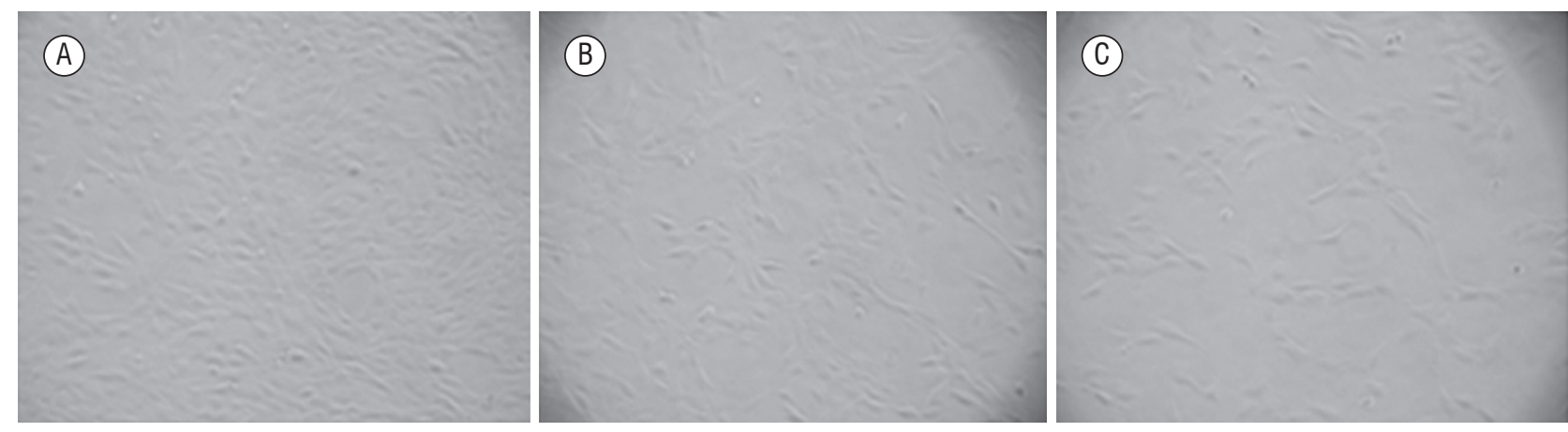

Figura 1 - Avaliação da morfologia das células musculares: (A) controle; (B) tratadas com o US; (C) tratadas com o LBP

A linhagem celular $\mathrm{C} 2 \mathrm{C} 12$ foi utilizada neste estudo, pois essas células são um subclone da linhagem de mioblastos $\mathrm{C} 2$, isoladas de células satélites de ratos adultos (51), que apresentam a maioria das características dos mioblastos normais e são comumente usadas como modelo para estudar a proliferação e a diferenciação de células musculares. $\mathrm{O}$ uso de linhagens celulares como modelo para a análise da proliferação celular elimina a possibilidade de o US e o laser de baixa potência interferirem na produção de fatores de crescimento de células não miogênicas contidas em culturas primárias, como fibroblastos e macrófagos $(49,52)$.

0 presente estudo avaliou os efeitos do US e LBP em células musculares após o processo de diferenciação celular com o intuito de acumular maior conhecimento acerca da utilização desses recursos para o reparo tecidual após lesões, distrofias e outras condições nas quais a proliferação de células musculares é requerida. Contudo, os resultados evidenciam que o US e o LBP não alteraram a proliferação das células musculares que permaneceram em meio de diferenciação por $96 \mathrm{~h}$. A comparação da proliferação celular nos períodos de $24 \mathrm{~h}$ e $72 \mathrm{~h}$ permitiu verificar que não houve aumento no número de células, o que comprova a eficiência do protocolo de diferenciação utilizado.

Contudo, estudos in vivo demonstram efeitos do US sobre o tecido muscular como verificado por Maddi et al. (30), que utilizaram o US pulsado em modelo experimental de lesão contusa em músculo gastrocnêmio de rato e encontraram um aumento na proliferação de células satélites. Além disso, em outros estudos verificaram que o tratamento com US melhora a extensibilidade muscular (42), a produção de força após lesão por contração (33) e pode aumentar a diferenciação das células musculares em modelo animal (37). Como o US acelera o processo de reparo em diversos estudos in vivo, é possível que esse efeito dependa da ação coordenada de diferentes tipos celulares presentes em tecidos adjacentes ao tecido muscular, como, por exemplo, o conjuntivo. Há a possibilidade de que o efeito do US e LBP no processo de reparo seja dependente da estimulação de outras células, que passariam a secretar fatores de crescimento envolvidos na proliferação e diferenciação das células musculares, em resposta aos recursos (53).

No entanto, outros autores que também utilizaram o modelo experimental animal foram igualmente incapazes de demonstrar aumento estatisticamente significativo na massa muscular ou na regeneração tecidual em lesões musculares tratadas com o US $(40,34)$. Essa controvérsia apoia a falta de evidência científica sobre a eficácia do US na reparação muscular $(25,32,37)$.

Estudos in vitro demonstraram que os efeitos do US foram dependentes dos parâmetros utilizados e do tipo celular, sendo capazes de promover a proliferação de osteoblastos, fibroblastos $(22,26$, 35,36 ), células endoteliais (33) e condrócitos (37). No entanto, outros autores não demonstraram de forma significativa os efeitos aditivos do US sobre a proliferação de fibroblastos (54), de células provenientes de discos intervertebrais de bovinos (33), de células uroepiteliais (36) ou até mesmo relataram diminuição no número de fibroblastos (34) após o tratamento com US.

Da mesma forma, o efeito de bioestimulação do LBP depende da combinação de parâmetros como comprimento de onda, potência, intensidade e também do tipo celular a ser avaliado $(39,40,42,43$, $46,47)$.

Segundo Almeida-Lopes e Marques, $(41,42)$ o laser é capaz de influenciar a proliferação de fibroblas- 
tos, osteoblastos (43) e células epiteliais (44). Além disso, essa terapia também possui efeitos sobre o colágeno e a síntese de colágeno $(45,42)$. Mais recentemente, um estudo analisou os efeitos do laser de AsGaAL nos parâmetros de $830 \mathrm{~nm}\left(0,3 \mathrm{~J} / \mathrm{cm}^{2}\right)$, $685 \mathrm{~nm}\left(0,6 \mathrm{~J} / \mathrm{cm}^{2}\right)$ e $670 \mathrm{~nm}\left(1,2 \mathrm{~J} / \mathrm{cm}^{2}\right)$ sobre células precursoras miogênicas e concluiu que a taxa de proliferação celular induzida por essas irradiações foi de $84,3 \%, 70,6 \%$ e $56,8 \%$, respectivamente (46).

0 presente estudo permitiu concluir que o US e o LBP, nos parâmetros utilizados, não foram capazes de alterar a proliferação das células musculares, em processo de diferenciação, porém há necessidade da realização de estudos posteriores para o melhor entendimento de outros possíveis efeitos desses recursos sobre essas células como, por exemplo, a utilização desses recursos como meio de prevenção à lesão e posterior diferenciação, para o estabelecimento de protocolos adequados a serem utilizados para o reparo muscular e recuperação clínica em atletas e pacientes.

\section{Agradecimento}

Agradecemos à Fapesp (2010/09191-5), ao CNPq e à UNINOVE pelo apoio financeiro.

\section{Referências}

1. Kumar A, Mohan S, Newton J, Rehage M, Tran K, Baylink DJ. Pregnancy-associated plasma protein-A regulates myoblast proliferation and differentiation through an insulin-like growth factor-dependent mechanism. J Biol Chem. 2005;280(45):37782-9.

2. Dogra C, Hall SL, Wedhas N, Linkhart TA, Kumar A. Fibroblast growth factor inducible-14 (Fn14) is required for the expression of myogenic regulatory factors and differentiation of myoblasts into myotubes: evidence for Tweak-independent functions of Fn14 during myogenesis. J Biol Chem. 2007; 282(20):15000-10.

3. Horsley V, Pavlath GK. Forming a multinucleated cell: molecules that regulate myoblast fusion. Cells Tissues Organs. 2004;176(1-3):67-78.

4. Chen Y, Zajac JD, MacLean HE. Androgen regulation of satellite cell function. J Endocrinol. 2005;186(1): $21-31$
5. Jansen KM, Pavlath GK. Mannose receptor regulates myoblast motility and muscle growth. J Cell Biol. 2006;174(3):403-13.

6. Dominov JA, Dunn JJ, Miller JB. Bcl-2 Expression identifies an early stage of myogenesis and promotes clonal expansion of muscle cells. J Cell Biol. 1998;142(2):537-44.

7. Cabane C, Englaro W, Yeow K, Ragno M, Dérijard B. Regulation of C2C12 myogenic terminal differentiation by MKK3/p38 pathway. Am J Physiol Cell Physiol. 2003;284(3):C658-66.

8. Tannu NS, Rao VK, Chaudhary RM, Saeed FGAE, Gao Y, Raghow R. Comparative proteomes of the proliferating $\mathrm{C} 2 \mathrm{C} 12$ myoblasts and fully differentiated myotubes reveal the complexity of the skeletal muscle differentiation Program. Mol Cell Proteomics. 2004;3(11):1065-82.

9. Schierholt AS, Fonseca I, Silva PV, Paiva SR, Chaves LCS, Lopes PS, et al. Análise filogenética do gene da miogenina. Arq Bras Med Vet Zootec. 2008; 60(1): 156-62.

10. Joulia D, Bernardi H, Garandel V, Rabenoelina F, Vernus B, Cabello G. Mechanisms involved in the inhibition of myoblast proliferation and differentiation by myostatin. Exp Cell Res. 2003;286(2):263-75.

11. Rios R, Carneiro I, Arce VM, Devesa J. Myostatin is an inhibitor of myogenic differentiation. Am J Physiol Cell Physiol. 2002;282(5):C993-9.

12. Langley B, Thomas M, Bishop A, Sharma M, Gilmour S, Kambadur R. Myostatin inhibits myoblast differentiation by down-regulating MyoD expression. J Biol Chem. 2002;277(51):49831-40.

13. Shi X, Garry DJ. Muscle stem cells in development, regeneration, and disease. Genes Dev. 2006;209(13): 1692-708.

14. Chargè SBP, Rudnicki MA. Cellular and molecular regulation of muscle regeneration. Physiol Rev. 2004; 84(1):209-38.

15. Foschini RMSA, Ramalho FS, Bicas HEA. Myogenic satellite cells. Arq Bras Oftalmol. 2004;67(4):681-7.

16. Holterman CE, Rudnicki MA. Molecular regulation of satellite cell function. Semin Cell Dev Biol. 2005; 16(4-5):575-84 
17. Demir H, Menku P, Kirnap M, Calis M, Ikizceli I. Comparison of the effects of laser, ultrasound, and combined laser ultrasound treatments in experimental tendon healing. Lasers Surg Med. 2004;35(1):84-9.

18. Galvão APL, Jorgetti V, Lopes da Silva O. Comparative study of how low-level laser therapy and low-intensity pulsed ultrasound affect bone repair in rats. Photomed Laser Surg. 2006;24(6):735-40.

19. Costa LOP, Costa LCM, Mendes PL, Cançado RL, Lara KL, Lima MD, et al. Effects of heating by ultrasound and aerobic activity on flexibility of the human triceps surae: a comparative study. Fisioter Mov. 2006; 19(2):19-24.

20. Johns LD. Nonthermal effects of therapeutic ultrasound: the frequency resonance hypothesis. J Athl Train. 2002;37(3):293-9.

21. Hsieh YL. Effects of ultrasound and diclofenac phonophoresis on inflammatory pain relief: suppression of inducible nitric oxide synthase in arthritic rats. Phys Ther. 2006;86(1):39-49.

22. Zhou S, Schmelz A, Seufferlein T, Li Y, Zhao J, Bachem MG. Molecular mechanisms of low intensity pulsed ultrasound in human skin fibroblasts. J Biol Chem. 2004;279(52):54463-9.

23. Vivino AA, Boraker DK, Miller D, Nyborg W. Stable cavitation at low ultrasonic intensities induces cell death and inhibits 3H-TdR incorporation by Con-AStimulated murine lymphocytes in vitro. Ultrasound Med Biol. 1985;11(5):751-9.

24. Ramirez A, Schwane JA, McFarland C, Starcher B. The effect of ultrasound on collagen synthesis and fibroblast proliferation in vitro. Med Sci Sports Exerc. 1997;29(3):326-32.

25. Fahnestock M, Rimer VG, Yamawaki PR, Edmonds PD. Effects of ultrasound exposure in vitro on neuroblastoma cell membranes. Ultrasound Med Biol. 1989;15(2):133-44.

26. De Deyne PG, Kirsch-Volders M. In vitro effects of therapeutic ultrasound on the nucleus of human fibroblast. Phys Ther. 1995;75(7):629-34.

27. Doan N, Reher P, Meghji S, Harris M. In vitro effects of therapeutic ultrasound on cell proliferation, protein synthesis and cytokine production by human fibroblasts, osteoblasts and monocytes. J Oral Maxillofac Surg. 1999;57(4):409-19.
28. Reher P, Doan N, Bradnock B, Meghji S, Harris M. Effect of ultrasound on the production of IL-8, basic FGF and VEGF. Cytokine. 1999;11(6):416-23.

29. Harle J, Mayia F, Olsen I, Salih V. Effects of ultrasound on transforming growth factor-B genes in bone cells. Eur Cell Mater. 2005;10:70-6.

30. Maddi A, Hai H, Ong ST, Sharp L, Harris M, Meghji S. Long wave ultrasound may enhance bone regeneration by altering OPG/RANKL ratio in human osteoblast-like cells. Bone. 2006;39(2):283-8.

31. Tang CH, Yang RS, Huang TH, Lu DY, Chuang WJ, Huang TF, et al. Ultrasound stimulates cyclooxygenase-2 expression and increases bone formation through integrin, focal adhesion kinase, phosphatidylinositol 3-kinase, and akt pathway in osteoblasts. Mol Pharmacol. 2006;69(6):2047-57.

32. Park K, Hoffmeister B, Han DK, Hasty K. Therapeutic ultrasound effects on interleukin-1B stimulated cartilage construct in vitro. Ultrasound Med Biol. 2007; 33(2):286-95.

33. Miyamoto K, An HS, Sah RL, Akeda K, Okuma M, Otten L, et al. Exposure to pulsed low intensity ultrasound stimulates extracellular matrix metabolism of bovine intervertebral disc cells cultured in alginate beads. Spine. 2005;30(21):2398-405.

34. Mukai S, Ito H, Nakagawa $Y$, Akiyama $H$, Miyamoto $M$, Nakamura T. Transforming growth factor B1 mediates the effects of low-intensity pulsed ultrasound in chondrocytes. Ultrasound Med Biol. 2005;31(12): 1713-21.

35. Lai JY, Pittelkow MR. Physiological effect of ultrasound mist on fibroblasts. Int J Dermatol. 2007; 46(6):587-93.

36. Hill GE, Fenwick S, Matthews BJ, Chivers RA, Southgate J. The effect of low-intensity pulsed ultrasound on repair of epithelial cell monolayers in vitro. Ultrasound Med Biol. 2005;31(12):1701-6.

37. Mizrahi N, Seliktar D, Kimmel E. Ultrasound-induced angiogenic response in endothelial cells. Ultrasound Med Biol. 2007;33(11):1818-29.

38. Warden RKF, Kessler CK, Avin KG, Cardinal RE, Stewart RL. Ultrasound produced by a conventional therapeutic ultrasound unit accelerates fracture repair. Phys Ther. 2006;86(8):1118-27. 
39. Fujihara NA. Estudo da adesão, proliferação e síntese de proteínas por osteoblastos cultivados e submetidos à ação do laser de baixa potência. [dissertação]. São Paulo: Faculdade de Odontologia da Universidade São Paulo; 2002.

40. Moore P, Ridgway TD, Higbee RG, Howard EW, Lucroy MD. Effect of wavelength on low-intensity laser irradiation-stimulated cell proliferation in vitro. Lasers Surg Med. 2005;36(1):8-12.

41. Almeida-Lopes L, Rigau J, Zângaro RA, Guiduli-Neto J, Jaeger MMM. Comparison of the low level therapy effects on cultured gingival fibroblasts proliferation using different irradiance and fluence. Lasers Surg Med. 2001;29(2):179-84.

42. Marques MM, Pereira NA, Fujihara NA, Nogueira FN, Eduardo CP. Effect of low-power laser irradiation on protein synthesis and ultrastructure of human gingival fibroblasts. Lasers Surg Med. 2004;34(3):260-5.

43. Fujihara NA, Hiraki KR, Marques MM. Irradiation at $780 \mathrm{~nm}$ increases proliferation rate of osteoblasts independently of dexamethasone presence. Lasers Surg Med. 2006;38(4):332-6.

44. Eduardo FP, Mehnert DU, Monezi TA, Zezell DM, Schubert MM, Eduardo CP, et al. Marques cultured epithelial cells response to phototherapy with low intensity laser. Lasers Surg Med. 2007;39(4):365-72.

45. Pereira AN, Eduardo CP, Matson E, Marques MM. Effect of low-power laser irradiation on cell growth and procollagen synthesis of cultured fibroblasts. Lasers Surg Med. 2002;31(4):263-7.

46. Amaral AC. Influência da terapia laser de baixa intensidade em células precursoras miogênicas (in vitro) e durante a regeneração muscular (in vivo). [dissertação]. São Carlos: Universidade Federal de São Carlos; 2004.

47. Azevedo LH, Eduardo FP, Moreira MS, Eduardo CP, Marques MM. Influence of different power densities of LILT on cultured human fibroblast growth. Lasers Med Sci. 2006;21(2):86-9.
48. Kreisler M, Christoffers AB, Willerstausen B, d'Hoedt B. Effect of low-level GaAIAS laser irradiation on the proliferation rate of human periodontal ligament fibroblasts: an in vitro study. J Clin Periodontal. 2003;30(4):353-8.

49. Lee MH, Jang MH, Kim EK, Han SW, Cho SY, Kim CJ. Nitric oxide induces apoptosis in mouse C2C12 myoblast cells. J Pharmacol Sci. 2005;97(3):369-76.

50. Löster K, Horstkorte R. Enzymatic quantification of cell-matrix and cell-cell adhesion. Micron. 2000; 31(1):41-53.

51. Yaffe D, Saxel D. Serial passaging and differentiation of myogenic cells isolated from dystrophic mouse muscle. Nature. 1977;270(5639):725-7.

52. Ferreira MPP, Ferrari RAM, Gravalos ED, Martins MD, Bussadori SK, Gonzalez DAB, et al. Effect of low-energy GaAlAs and InGaAlP laser irradiation on the viability of C2C12 myoblasts in a muscle injury model. Photomed Laser Surg. 2009;27(6):901-6.

53. Artilheiro PP, Oliveira EN, Viscardi CS, Martins MD, Bussadori SK, Fernandes KPS, et al. Efeitos do ultra-som terapêutico contínuo sobre a proliferação e viabilidade de células musculares C2C12. Fisioter Pesq. 2010;17(2):167-72.

54. Oliveira RF, Oliveira DA, Monteiro W, Zangaro RA, Magini M, Soares CP. Comparison between the effect of low-level laser therapy and low-intensity pulsed ultrasonic irradiation in vitro. Photomed Laser Surg. 2008;26(1):6-9.

Recebido: 23/11/2010

Received: $11 / 23 / 2010$

Aprovado: $16 / 06 / 2011$

Approved: 06/16/2011 